\title{
Ectopic Endometriosis Seeded to the Rectus Muscle
}

\author{
Gabriel O. Ologun ${ }^{1}$, Cara Hannigan ${ }^{1}$, Edmund Kwarteng ${ }^{2}$, Aaron Bambil ${ }^{2}$, David Bertsch ${ }^{3}$ \\ 1. General Surgery, Robert Packer Hospital/Guthrie Clinic, Sayre, USA 2. Family Medicine, Caribbean Medical \\ University, Cupecoy, CUW 3. Surgical Oncology, Robert Packer Hospital/Guthrie Clinic, Sayre, USA
}

Corresponding author: Gabriel O. Ologun, gabe.ologun@gmail.com

\begin{abstract}
Endometriosis is a pathological condition whereby endometrial glands and stroma are located outside the physiologically expected location, the uterus. A lesion is usually located in the pelvis but can also occur in the diaphragm, bowel, pleural cavity, or surgical scar. It is a benign estrogen-dependent condition. Here, we present the case of a 40-year-old woman with ectopic endometriosis.
\end{abstract}

Categories: Family/General Practice, Obstetrics/Gynecology, General Surgery

Keywords: endometriosis, scar endometriosis, hormonal suppression, rectus muscle, abdominal mass

\section{Introduction}

Surgical scar endometriosis is a rare condition that is very difficult to diagnose because of its nonspecific symptoms. The patient may present with pain at the incision site from previous surgery (abdominal pain in the region of the scar). The pain may be cyclical, intensifying during the menstrual period. Some patients may present, in addition to the symptoms above, with some leakage from the scar area [1]. Here, we present the case of a 40-year-old woman with ectopic endometriosis. Informed consent was obtained.

\section{Case Presentation}

A 40-year-old woman, who has had one pregnancy and has delivered once (G1P1), was referred by her gynecologist to our surgical oncology clinic for evaluation of a lower midline abdominal wall mass. The patient reported having abdominal pain and discomfort in this area for more than five years, with no definite sense of lump or mass, and worsening pain immediately prior to and during her menses. Personal history revealed that she had a planned lower segment cesarean section several years ago. She was recently diagnosed with dysfunctional uterine bleeding. She is not taking any medication at home.

Received 08/21/2019

Review began 08/21/2019 Review ended 09/13/2019 Published 10/09/2019

\section{() Copyright 2019}

Ologun et al. This is an open access article distributed under the terms of the Creative Commons Attribution License CC-BY 3.0., which permits unrestricted use, distribution, and reproduction in any medium, provided the original author and source are credited.
Her physical examination revealed a palpable tender subcutaneous mass located under the incision scar. Sonography and Doppler examination of the abdomen revealed a $5 \mathrm{~cm} \mathrm{x} 3 \mathrm{~cm}$ heterogeneous hypoechoic mass, with an otherwise normal examination of the uterus and ovaries (Figure 1). Computed tomography (CT) scan revealed a $6.2 \times 6.8 \times 3.6 \mathrm{~cm}$ complex cystic lesion involving the rectus muscle and fascia without traversing the peritoneum (Figure 2).

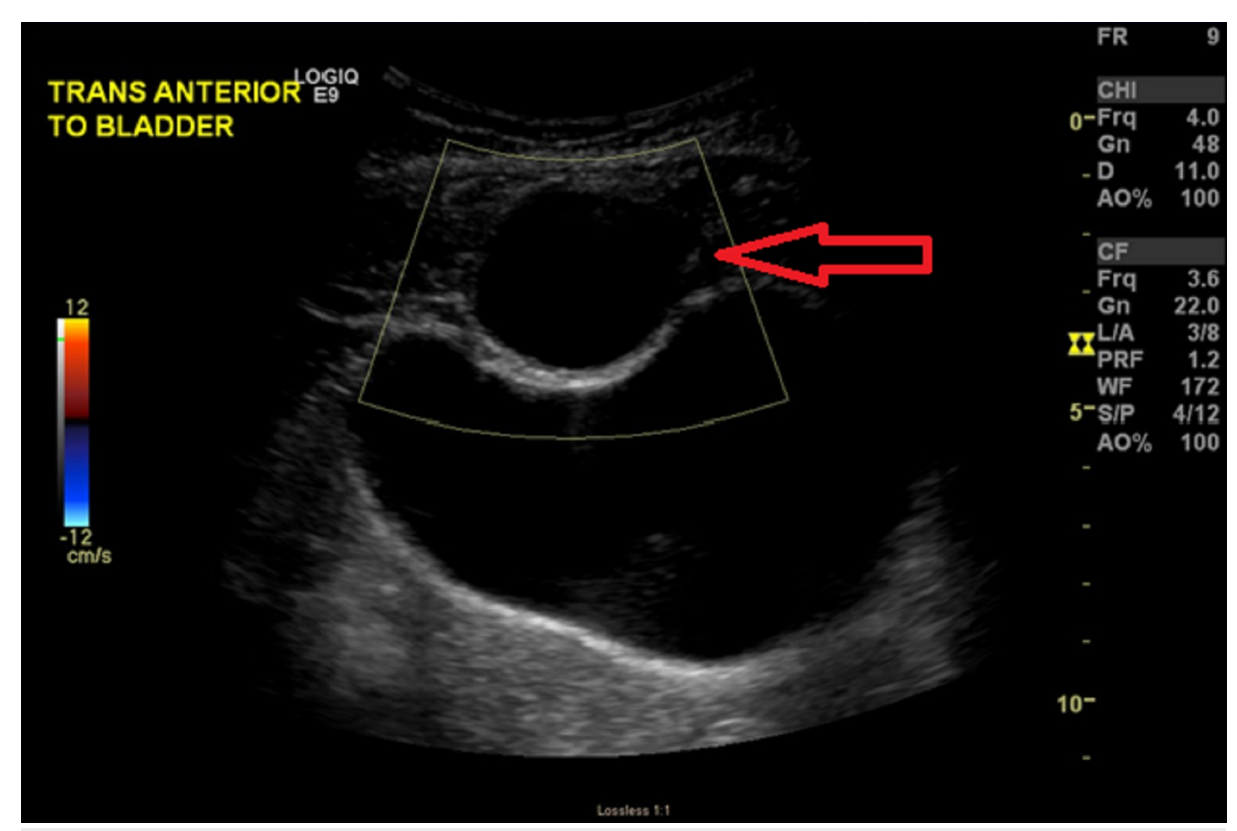




\section{Cureus}

FIGURE 1: Sonography and Doppler examination of the abdomen revealing a $5 \mathrm{~cm} \times 3 \mathrm{~cm}$ heterogeneous hypoechoic mass (arrow)

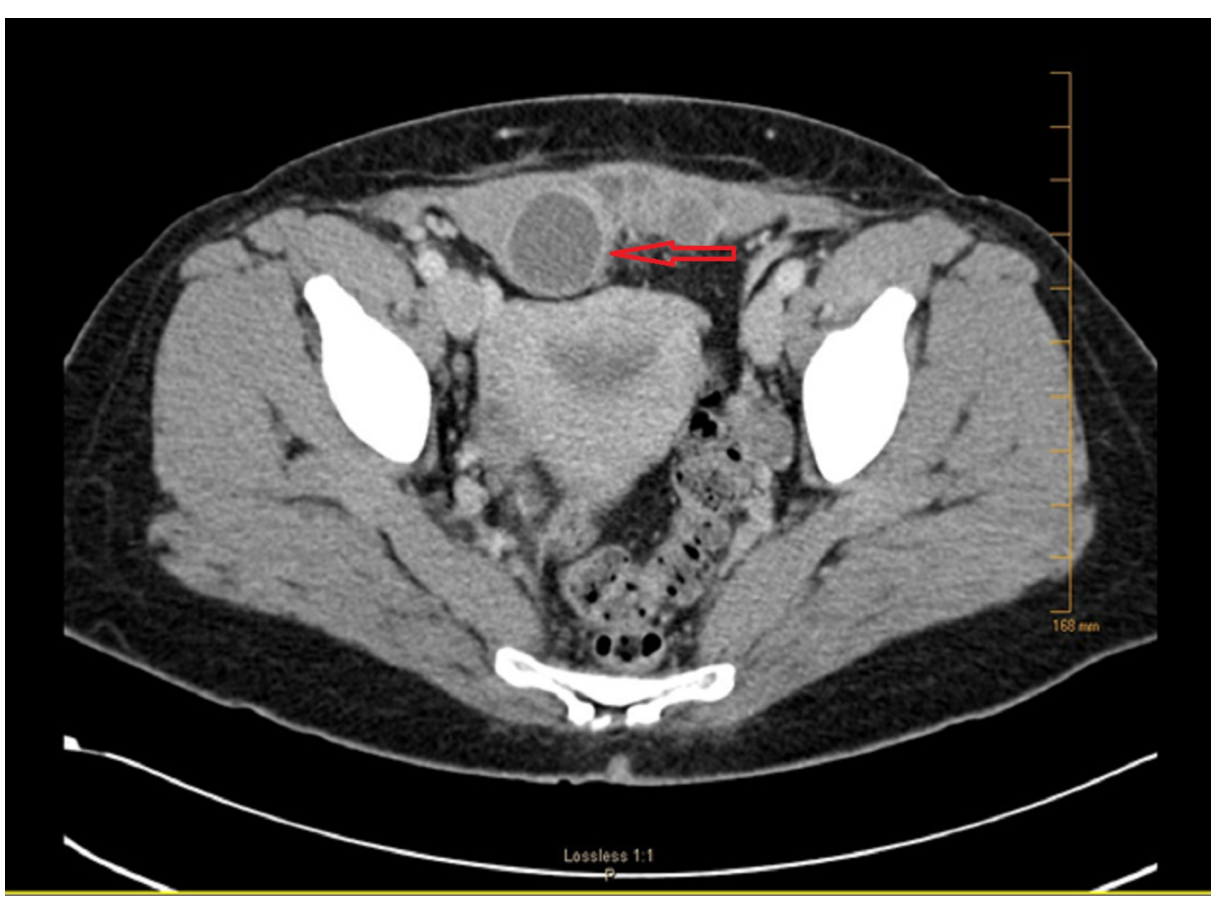

FIGURE 2: Axial computed tomography scan revealing a $6.2 \times 6.8 \times 3.6$ $\mathrm{cm}$ complex cystic lesion involving the rectus muscle (arrow)

Fine needle aspiration revealed amorphous debris, hemorrhage, and hemosiderin cystic degeneration, negative for malignant cells. An ultrasound-guided core needle biopsy of the abdominal wall mass was conducted by an interventional radiologist, and pathology revealed benign endometrial glands and stroma compatible with endometriosis with active inflammation and fibrosis. Test results were negative for epithelial dysplasia.

She was managed with hormonal therapy (Lupron ${ }^{\circledR}$ ). Six months into treatment with hormonal therapy, her abdominal pain, and vaginal bleeding resolved, and she had no awareness or feeling of an abdominal mass. A CT scan revealed marked shrinkage of the abdominal mass (Figure 3). 


\section{Cureus}

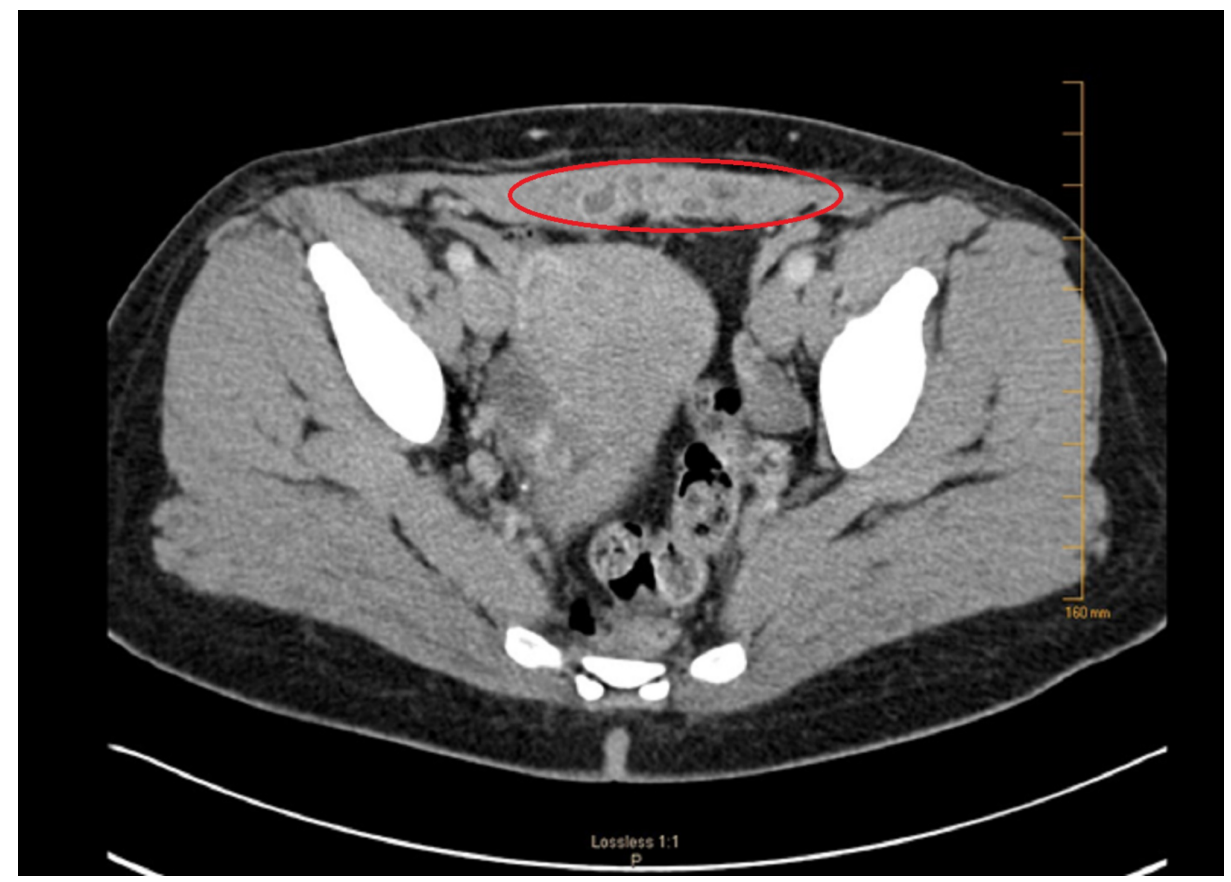

FIGURE 3: Six-month follow-up axial computed tomography scan revealing marked shrinkage of the abdominal mass (oval ring) while on hormonal therapy

At the 12-month follow-up, the patient was discontinued on hormonal therapy for approximately two months, her menses were regular, and she had no abdominal pain. A CT scan revealed further shrinkage of the abdominal mass (Figure 4 ).

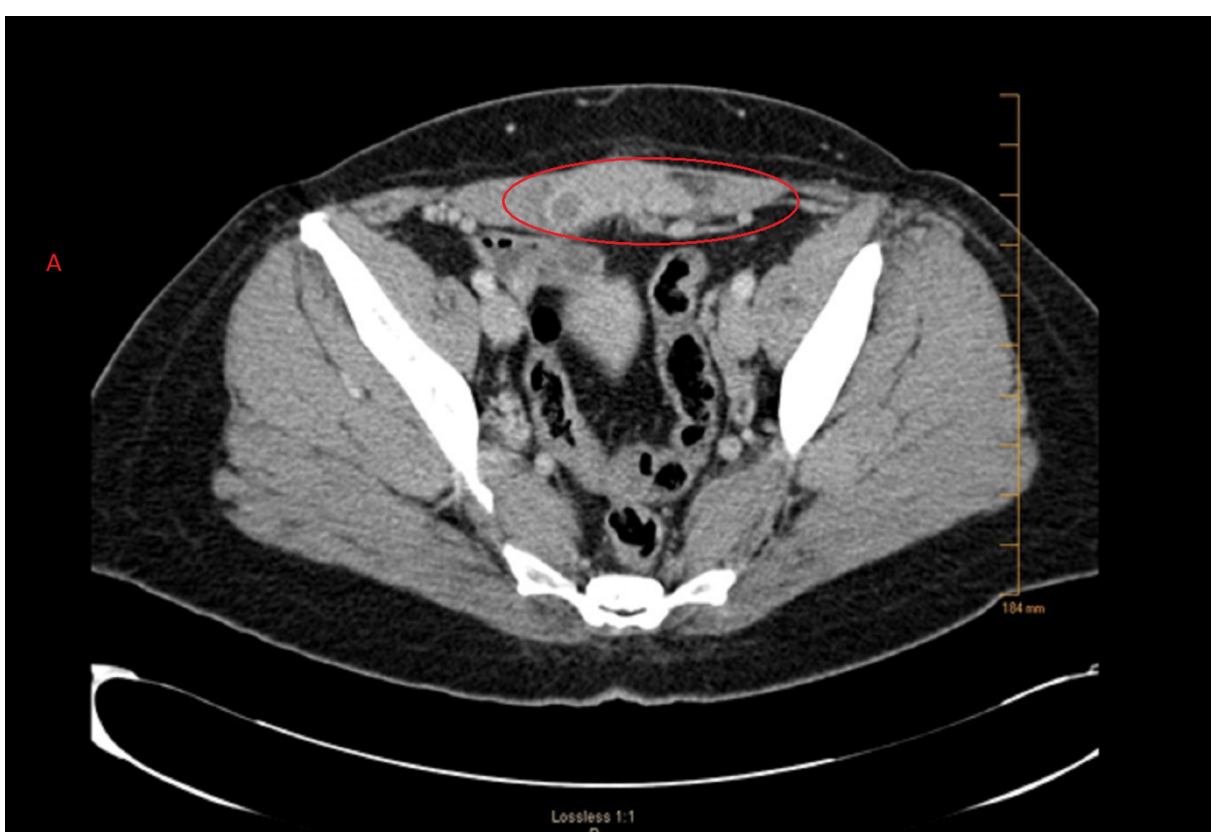

FIGURE 4: At 12-month follow-up, patient was two months off hormonal therapy, and axial computed tomography scan revealed abdominal mass remained shrunken (oval ring)

At that time, we discussed options such as observation, radiation therapy, or surgical resection. Surgical resection would have been an extensive procedure given the location and a full-thickness involvement of the medial aspect of the bilateral rectus muscles. The patient elected to continue with observation and follow- 


\section{Discussion}

Due to its asymptomatic nature in some women, determining the prevalence of ectopic endometriosis can be a daunting task. However, surgery is the definitive diagnostic means [2]. Endometriosis affects approximately $6 \%$ to $10 \%$ of women of reproductive age. Patients usually present with dysmenorrhea, dyspareunia, chronic pelvic pain, and infertility [3]. The incidence of affected women who experience pain, infertility, or both can be as high as $35 \%$ to $50 \%$ [4].

In decreasing order of frequency, the most common anatomic sites for this lesion are ovaries, posterior and anterior cul-de-sac, posterior broad ligaments, uterosacral ligaments, uterus, fallopian tubes, sigmoid colon, and appendix and round ligaments [5].

Associated risk factors for ectopic endometriosis include nulliparity [6] and prolonged exposure to endogenous estrogen, such as early menarche or late menopause [7]. Heavy menstrual bleeding, obstruction of menstrual outflow, and high consumption of transunsaturated fats are also risk factors [8]. Risk factors for developing surgical scar endometriosis can include women who have undergone prior abdominal or pelvic operation, hysterotomy in the second or third trimester, alcohol consumption, increased menstrual flow, and obesity $[1,8,9]$.

Sonography and Doppler examinations can reveal heterogeneous hypoechoic mass with echogenic spots. Diagnosis can be confirmed with excision and analysis of tissue samples from the area, and examination will reveal fibrosis of the tissue that involves the fascia of the area as well [9].

Surgery is the definitive treatment for endometriosis and must be performed with clear margins and followed up with reconstruction of the damaged tissue. Hormone suppression has also been suggested since hormone induction due to surgical procedure is a suspected cause of the condition [9]. Preventive measures include a thorough isolation of the incision site and cleaning of the pelvic cavity before closure of the abdominal wall postsurgery [9].

\section{Conclusions}

Surgical scar endometriosis is a rare condition that is difficult to diagnose. Surgery is the definitive diagnosis and management. However, in carefully selected patients, hormonal suppression has been used to successfully manage this condition, as evidenced in our case presentation.

\section{Additional Information \\ Disclosures}

Human subjects: Consent was obtained by all participants in this study. Conflicts of interest: In compliance with the ICMJE uniform disclosure form, all authors declare the following: Payment/services info: All authors have declared that no financial support was received from any organization for the submitted work. Financial relationships: All authors have declared that they have no financial relationships at present or within the previous three years with any organizations that might have an interest in the submitted work. Other relationships: All authors have declared that there are no other relationships or activities that could appear to have influenced the submitted work.

\section{References}

1. Khachani I, Filali Adib A, Bezad R: Cesarean scar endometriosis: an uncommon surgical complication on the rise? Case report and literature review. Case Rep Obstet Gynecol. 2017, 2017: 10.1155/2017/8062924

2. Nnoaham KE, Hummelshoj L, Webster P, et al.: Impact of endometriosis on quality of life and work productivity: a multicenter study across ten countries. Fertil Steril. 2011, 96:366-373. 10.1016/j.fertnstert.2011.05.090

3. Burney RO, Giudice LC: Pathogenesis and pathophysiology of endometriosis. Fertil Steril. 2012, 98:511-519. 10.1016/j.fertnstert.2012.06.029

4. Meuleman C, Vandenabeele B, Fieuws S, Spiessens C, Timmerman D, D'Hooghe T: High prevalence of endometriosis in infertile women with normal ovulation and normospermic partners. Fertil Steril. 2009, 92:68-74. 10.1016/j.fertnstert.2008.04.056

5. Gustofson RL, Kim N, Liu S, Stratton P: Endometriosis and the appendix: a case series and comprehensive review of the literature. Fertil Steril. 2006, 86:298-303. 10.1016/j.fertnstert.2005.12.076

6. Sinaii N, Plumb K, Cotton L, et al.: Differences in characteristics among 1,000 women with endometriosis based on extent of disease. Fertil Steril. 2008, 89:538-545. 10.1016/j.fertnstert.2007.03.069

7. Giudice LC: Clinical practice. Endometriosis. N Engl J Med. 2010, 362:2389-2398. 10.1056/NEJMcp1000274

8. Missmer SA, Chavarro JE, Malspeis S, et al.: A prospective study of dietary fat consumption and endometriosis risk. Hum Reprod. 2010, 25:1528-1535. 10.1093/humrep/deq044

9. Danielpour PJ, Layke JC, Durie N, Glickman LT: Scar endometriosis - a rare cause for a painful scar: a case report and review of the literature. Can J Plast Surg. 2010, 18:19-20. 10.1177/229255031001800110 